\title{
Real-World Experience with Dupilumab in Severe Asthma: One-Year Data from an Italian Named Patient Program
}

\author{
Raffaele Campisi $\mathbb{1}^{\prime}$ \\ Claudia Crimi (iD) \\ Santi Nolasco iD ${ }^{2}$ \\ Bianca Beghè ${ }^{3}$ \\ Leonardo Antonicelli (iD ${ }^{4}$ \\ Gabriella Guarnieri ${ }^{5}$ \\ Nicola Scichilone iD ${ }^{6}$ \\ Morena Porto ${ }^{2}$ \\ Luigi Macchia $^{7}$ \\ Giulia Scioscia iD ${ }^{8}$ \\ Maria Pia Foschino Barbaro ${ }^{8}$ \\ Alberto Papi (iD ${ }^{9}$ \\ Nunzio Crimi ${ }^{1,2}$

\begin{abstract}
'Respiratory Medicine Unit, A.O.U. Policlinico "G. Rodolico -San Marco", Catania, Italy; ${ }^{2}$ Department of Clinical and Experimental Medicine, Section of Respiratory Diseases, University of Catania, Catania, Italy; ${ }^{3}$ Respiratory Medicine Unit, Department of Medicine, University of Modena and Reggio Emilia, Modena, Italy; ${ }^{4}$ Allergy Unit, Department of Internal Medicine, Ancona University Hospital, Ancona, Italy; ${ }^{5}$ Department of Cardiac, Thoracic and Vascular Sciences, University-City Hospital of Padova, Padova, Italy; ${ }^{6}$ University of Palermo, PROMISE Department, University of Palermo, Palermo, Italy; ${ }^{7}$ Department of Emergency and Organ Transplantation, School and Chair of Allergology and Clinical Immunology, University of Bari, Bari, Italy; ${ }^{8}$ Department of Medical and Surgical Sciences, Institute of Respiratory Diseases, University of Foggia, Foggia, Italy; ${ }^{9}$ Respiratory Medicine Unit, S. Anna University Hospital, Ferrara, Italy
\end{abstract}

Correspondence: Claudia Crimi Respiratory Medicine Unit, A.O.U. Policlinico "G. Rodolico - San Marco", Catania, Italy

Email dott.claudiacrimi@gmail.com
Introduction: Dupilumab is a monoclonal antibody targeting IL-4R $\alpha$ recently licensed for severe asthma (SA). A Named Patients Program (NPP) was created in Italy before its commercial availability for SA patients with no other available therapeutic options. We aimed to assess the real-world effectiveness of dupilumab in patients with SA and unmet needs.

Methods: We performed a multicentre retrospective study, including SA patients admitted to the NPP treated with dupilumab for 12 months. Data on the number of exacerbations, Asthma Control Test (ACT), pre-bronchodilator $\mathrm{FEV}_{1} \%$, oral corticosteroids (OCSs) use, FeNO and eosinophils count in peripheral blood were recorded at baseline and after 3, 6, and 12 months.

Results: We included 18 SA patients (mean age $53.3 \pm 12.4$ years, $66.7 \%$ female). Eleven (61.1\%) were OCSs dependent. Five patients (27.8\%) received previous anti-IgE and/or antiIL-5 agents. A significant improvement in ACT score (from 15.7 \pm 5.1 to $18.8 \pm 4.8, \mathrm{p}=0.023$ ), OCSs intake [10 (5-25) mg/day to $0(0-5) \mathrm{mg} /$ day, $\mathrm{p}=0.0333$ ] and FeNO [from 25 (20-80) ppb to $21(10.9-55.3) \mathrm{ppb}, \mathrm{p}=0.0190$ ] was already detected after 3 months of treatment. After 12 months, a statistically significant decrease in the number of exacerbations from $2(0-3)$ to $0(0-1)(\mathrm{p}<0.0068)$ and increase in $\mathrm{FEV}_{1} \%$ from $73.5 \pm 19.5 \%$ to $87.1 \pm 19.2 \%(\mathrm{p}=0.0407)$ and ACT to a mean value of $22.4 \pm 1.7(\mathrm{p}<0.0001)$ and the interruption of OCSs in all the patients $(\mathrm{p}<0.0001)$ was observed. A transient increase in the eosinophil count was observed in five patients (above 1000 cells/ $\mu \mathrm{L}$ in 2 cases) after 3 months, without any clinical effect.

Conclusion: Dupilumab improved all the explored clinical outcomes after 12 months, and the transient hypereosinophilia did not modify treatment response. These real-world data confirm the results reported in randomized controlled trials and provide an important opportunity to characterize the clinical impact of the treatment in a non-trial setting. Further real-world studies with a larger cohort of patients are needed to confirm these findings.

Keywords: severe asthma, Named Patient Program, oral corticosteroids, real-world, dupilumab

\section{Introduction}

Asthma is a largely diffuse chronic respiratory disorder characterized by airway inflammation, hyperresponsiveness of bronchi and often reversible bronchial obstruction. As a consequence, it may have a relevant impact on daily symptoms and can be a trigger for unpredictable acute exacerbations. 
Although most asthma patients are well controlled with current standard therapies, about $3.7-10 \%$ of them are affected by severe asthma (SA). ${ }^{1,2} \mathrm{SA}$ is defined as an uncontrolled disease despite high-dose inhaled corticosteroids (ICS) and long-acting $\beta 2$-adrenergic agonists (LABA). ${ }^{3}$ It often requires additional treatments, such as oral corticosteroids (OCSs), whose chronic use is responsible for several side-effects, including osteoporosis, diabetes, cataract, anxiety, and depression, increasing the already high SA-related economic burden. ${ }^{4}$ Type 2 inflammation, mediated by cytokines, such as interleukin-4 (IL4), interleukin-5 (IL-5), and interleukin-13 (IL-13), occurs in approximately $50 \%$ of asthmatic patients. ${ }^{5}$

SA treatment evolved over the past decade as several monoclonal antibody therapies have been licensed, such as targeting IgE (omalizumab), IL-5 (mepolizumab), and IL$5 \mathrm{R} \alpha$ (benralizumab).

Dupilumab is a fully human monoclonal antibody directed against the alpha subunit of the IL-4 receptor (IL-4R $\alpha$ ), blocking both IL-4 and IL-13 pathways, ${ }^{6}$ firstly designed for the treatment of moderate-to-severe atopic dermatitis (AD) ${ }^{7}$ and subsequently evaluated in patients with chronic rhinosinusitis with nasal polyps $(\mathrm{CRSwNP})^{8}$ and SA. ${ }^{9,10}$ Indeed, clinical trials ${ }^{9,10}$ showed that dupilumab is able to significantly reduce the rate of severe asthma exacerbations, to improve lung function and to reduce OCSs intake in patients with uncontrolled moderate-to-severe asthma.

Dupilumab was approved for the treatment of SA by the European Medicines Agency (EMA) in March 2019 and by the Italian Drug Agency (AIFA) in December 2020. Nevertheless, in September 2018, AIFA authorized the use of dupilumab according to the Named Patient Program (NPP) in patients with uncontrolled SA without further available treatment options.

In this retrospective, multicentre, real-life, observational study, we aimed to describe the clinical characteristics of patients involved in the NPP and the effectiveness of dupilumab in improving asthma exacerbations, pulmonary function, and Asthma Control Test (ACT), after 3, 6 and 12 months of treatment.

\section{Materials and Methods Study Design}

We performed a multi-center, retrospective, observational study on all SA patients admitted to dupilumab NPP. Patients were enrolled in highly specialized outpatient facilities for the treatment of SA of 8 Italian hospitals [(1) A.O.U. Policlinico "G. Rodolico - San Marco", Catania; (2) A.O.U. "Policlinico Giaccone", Palermo; (3) Azienda Ospedale Università Padova, Padova; (4) A.O.U. “Arcispedale Sant'Anna”, Ferrara; (5) A.O.U. di Modena, Policlinico di Modena, Modena; (6) A.O.U. Policlinico di Bari "Giovanni XXIII", Bari; (7) Azienda Ospedaliero Universitaria di Foggia, Foggia; (8) A.O.U. Ospedali Riuniti di Ancona, Ancona] between September 2018 and April 2019. This study followed the Declaration of Helsinki, met the standards of Good Clinical Practice (GCP), and was also approved by the Ethics Committee "Catania 1" at the Policlinico Hospital (Protocol Number 33/2020/PO - April 6th 2020). All patients signed a written informed consent.

\section{Patient Population}

Patients aged more than 18 years, with a diagnosis of SA according to the European Respiratory Society/American Thoracic Society (ERS/ATS) guidelines ${ }^{1}$ and with confirmed adherence to maintenance therapy, based on both the assessment of how often the medications were refilled and correct inhalations technique, were included. To admit a patient into the NPP, physicians had to certify to the Italian Drug Agency (AIFA) and the local Ethics Committee that the patient had an uncontrolled SA and/ or severe steroid side-effects, requiring an urgent step-up treatment without further therapeutical options. The authorization for treatment was given by the local Ethics Committees, AIFA and the drug manufacturer Sanofi. A blood eosinophil count $\geq 150$ cells $/ \mu \mathrm{L}$ or $\mathrm{FeNO} \geq 25$ ppb were not required since the prescribing criteria were not established at the time. Patients with a peripheral blood eosinophil count $\geq 1500$ cells $/ \mu \mathrm{L}$ in the previous year were excluded from the NPP in order to avoid cases of symptomatic hypereosinophilia. ${ }^{11}$ Dupilumab was administered every 2 weeks, starting with a loading dose of $600 \mathrm{mg}$ and then maintaining doses of $300 \mathrm{mg} .{ }^{11}$

\section{Data Collection and Assessment}

Demographic [age, sex, body mass index (BMI)], asthma characteristics (age at onset, skin prick test to evaluate sensitization to common aeroallergens, maintenance therapies, previous anti-IgE and/or anti-IL-5 agents, total IgE count, asthma exacerbations in the previous year) and comorbidities [chronic rhinosinusitis with (CRSwNP) or without (CRSsNP) nasal polyps, gastroesophageal reflux (GERD), atopic dermatitis] were collected at baseline. 
Number of exacerbations, pulmonary function tests, blood eosinophils count, fractional exhaled nitric oxide (FeNO), Asthma Control Test (ACT) score, ${ }^{12,13}$ and daily OCSs intake (prednisone $\mathrm{mg} /$ day) were assessed before starting the therapy with dupilumab and after 3, 6, and 12 months of treatment. Asthma exacerbations were defined as a disease worsening requiring $\geq 3$ days of treatment with OCSs (or a double daily dose if already on OCSs). ${ }^{14}$ One patient had 2 exacerbations treated with cycles of corticosteroids $<7$ days from each other and were considered as the same exacerbation. Lung function tests were performed according to ERS/ATS guidelines. ${ }^{15}$

\section{Statistical Analysis}

An established database was accessed for data analysis. Categorical variables are stated as number (n) and percentage (\%). Normally distributed continuous variables are expressed as mean \pm standard deviation (SD). Median and interquartile range (IQR) is used in the case of continuous nonparametric variables. Fisher exact or ChiSquare tests were used for comparisons of categorical variables. The normality of data distribution was checked using Kruskal-Wallis and Kolmogorov-Smirnov tests. Student $t$ test, Mann-Whitney $U$-test, Dunnett's multiple comparison test and Friedman test with Dunn's post-hoc were used to compare variables, when appropriate. Statistical analysis and figures were generated using Prism version 9.0.0 (GraphPad Software Inc). A p-value $<0.05$ (two-sided) was considered statistically significant.

\section{Results}

\section{Patients' Characteristics}

Eighteen subjects were included in the NPP. Baseline patients' characteristics are reported in Table 1. In particular, the mean age of the patients was $53.3 \pm 12.4$ years and mean age at onset was $32.7 \pm 18.1$ years; 12 out of 18 $(12 / 18,66.7 \%)$ patients were female. Over half of our patients $(10 / 18,55.6 \%)$ had positive skin prick tests; 15 patients $(83.3 \%)$ had chronic rhinosinusitis, and 7 (38.9\%) moderate-to-severe CRSwNP. All patients were treated with high-dose ICSs-LABAs; a long-acting muscarinic antagonist (LAMA) was added to this combination in $61.1 \%(11 / 18)$ of cases. Eleven patients (61.1\%) were OCSs dependent [median dose $10(5-25) \mathrm{mg} /$ day]. Five patients $(5 / 18,27.8 \%)$ received a previous treatment with anti-IgE and/or anti-IL-5 agents, which were suspended for at least 4 months before starting dupilumab, due to the lack of response. During the 12 months prior to the anti-IL $-4 \mathrm{R} \alpha$ treatment, the median annual exacerbation rate was 2 (0-3). In $7 / 18(38.9 \%)$ the blood eosinophil count at baseline was $<300$ cells $/ \mu \mathrm{L}$.

\section{Dupilumab Efficacy on Severe Asthma}

The administration of dupilumab was able to improve all the evaluated outcomes after 12 months of treatment (Table 2). Asthma exacerbations significantly decreased from $2(0-3)$ to $0(0-1) \quad(p=0.0068)$ (Figure 1A). Consequently, ACT score improved from mean 15.7 \pm 5.1 to $18.8 \pm 4.8(\mathrm{p}=0.023)$ after 3 months of treatment, reaching 22.4 $\pm 1.7(\mathrm{p}<0.0001)$ at month 12 (Figure 1B). Sixteen patients $(88.9 \%)$ achieved an $\mathrm{ACT}$ score equal to or greater than 20, a critical value indicative of a good overall asthma control. Furthermore, $66.7 \%$ of patients reported an ACT score increase $\geq 3$ points (MCID) $^{16}$ at the end of the follow-up. Pulmonary function also benefited from dupilumab add-on treatment, with a significant $\mathrm{FEV}_{1} \%$ improvement after 12 months (from $73.5 \pm 19.5 \%$ to 87.1 $\pm 19.2 \%, \mathrm{p}=0.0407$ ) (Figure 1C). All 11 patients on OCSs were able to discontinue the steroid treatment $(\mathrm{p}<0.0001)$ with a significative daily-dose reduction after 3 months [from $10(5-25) \mathrm{mg} /$ day to $0(0-5) \mathrm{mg} /$ day, $\mathrm{p}=0.0333$ ] (Figure 2A and B). FeNO also decreased from a median value of 25 (20-80) ppb to $21(10.9-55.3) \mathrm{ppb}(\mathrm{p}=0.0190)$ after 3 months and to 14 (10-20) ppb after 12 (Figure 2C).

\section{Blood Eosinophil Count During Treatment}

The median blood eosinophil count progressively reduced during the treatment from $320(190-532.5)$ cells $/ \mu \mathrm{L}$ at baseline to $225(106.3-397.5)$ cells $/ \mu \mathrm{L}(\mathrm{p}<0.0038)$ after 12 months of treatment (Figure 3). Nevertheless, we observed an increase of this value from baseline in 5 patients $(27.8 \%)$ after 3 months, in $4(22.2 \%)$ patients after 6 months, and in 2 $(11.1 \%)$ patients after 12 months. In only two patients the threshold of 1000 cells/ $\mu \mathrm{L}$ was exceeded (at month 3 ); in one case, the blood eosinophil count reached 3000 cells $/ \mu \mathrm{L}$ starting from a baseline count of 1410 cells $/ \mu \mathrm{L}$.

Vasculitis and allergic bronchopulmonary aspergillosis were excluded, the latter since no patients had a positive prick test for Aspergillus, total IgE count $>1000 \mathrm{IU} / \mathrm{mL}$ and related symptoms (dyspnea, fever and asthma worsening). ${ }^{17}$ As such, these hypereosinophilic cases were considered asymptomatic without affecting the efficacy of dupilumab. 
Table I Patients Baseline Demographic and Clinical Characteristics

\begin{tabular}{|c|c|}
\hline & All $(n=18)$ \\
\hline Age, years, mean (SD) & $53.3(12.4)$ \\
\hline Female, n (\%) & $12(66.7)$ \\
\hline BMI, mean (SD) & $28.3(4.2)$ \\
\hline Age at onset, years, mean (SD) & $32.7(18.1)$ \\
\hline Positive Skin Prick Test, n (\%) & $10(55.6)$ \\
\hline CRSwNP, n (\%) & $7(38.9)$ \\
\hline CRSsNP, n (\%) & $8(44.4)$ \\
\hline Atopic Dermatitis, n (\%) & I (5.6) \\
\hline GERD, n (\%) & $5(27.8)$ \\
\hline High dose ICS-LABA, n (\%) & $18(100)$ \\
\hline LAMA, n (\%) & II (6I.I) \\
\hline Patients on OCS, n, (\%) & II (6I.I) \\
\hline OCS, mg/day, median (IQR) & $10(5-25)$ \\
\hline Previous anti-IgE/anti IL-5 mAbs, n (\%) & $5(27.8)$ \\
\hline Asthma exacerbations/year, median (IQR) & $2(0-3)$ \\
\hline $\mathrm{ACT}$, mean (SD) & I5.7 (5.1) \\
\hline $\mathrm{FEV}_{1}, \%$, mean $(\mathrm{SD})$ & $73.5(19.5)$ \\
\hline $\mathrm{FEV}_{1}$, L, mean (SD) & $2.13(1.1)$ \\
\hline FeNO, ppb, median (IQR) & $25(20-80)$ \\
\hline Patients with FeNO $<25 \mathrm{ppb}$ & $7(38.9)$ \\
\hline Eosinophil counts in peripheral blood, cells/ $\mu \mathrm{L}$ median (IQR) & $320(190-532.5)$ \\
\hline Patients with eosinophil counts in peripheral blood $\geq 300$ cells $/ \mu \mathrm{L}$ & II (6I.I) \\
\hline Patients with eosinophil counts in peripheral blood $\geq 150$ and $<300$ cells $/ \mu \mathrm{L}$ & $5(27.8)$ \\
\hline Patients with eosinophil counts in peripheral blood $<150$ cells $/ \mu \mathrm{L}$ & $2(I I . I)$ \\
\hline $\operatorname{lgE}, \mathrm{Ul} / \mathrm{mL}$, mean (SD) & $135(57.4)$ \\
\hline
\end{tabular}

Notes: Normally distributed data are presented as mean and standard deviation (SD). Non-normally distributed variables are presented as median and interquartile range (IQR).

Abbreviations: BMI, body mass index; CRSwNP, chronic rhinosinusitis with nasal polyps; CRSsNP, chronic rhinosinusitis without nasal polyps; GERD, gastroesophageal reflux disease; ICS-LABA, inhaled corticosteroids - long-acting beta-agonist; LAMA, long-acting muscarinic antagonist; OCS, oral corticosteroids (prednisone); ACT, Asthma Control Test; $\mathrm{FEV}_{1}$, forced expiratory volume in the Ist second; FeNO, fractional exhaled nitric oxide; IgE, immunoglobulin-E.

\section{Response According to Blood Eosinophil Count and FeNO Values at Baseline}

To evaluate the clinical response according to the baseline blood eosinophil count, we compared patients with $<300$ cells $/ \mu \mathrm{L}$ ( 7 patients) vs $\geq 300$ cells $/ \mu \mathrm{L}$ (11 patients). As shown in Table 3, ACT score ( $21 \pm 4.42$ vs $23 \pm 0.9, \mathrm{p}=0.4791$ ),
$\mathrm{FEV}_{1}(93.2 \pm 22.7 \%$ vs $83.8 \pm 17.5 \%, \mathrm{p}=0.4010)$ and $\mathrm{OCSs}$ use (no patients on OCSs after 12 months) were comparable in both groups after 12 months. Similarly, patients with a FeNO value $<25 \mathrm{ppb}$ (7 patients) or $\geq 25 \mathrm{ppb}$ (11 patients) showed no statistically significant differences at the end of the follow-up. 
Table 2 Outcomes After 3 and 12 Months of Treatment

\begin{tabular}{|c|c|c|c|c|c|}
\hline Total $n=18$ & Baseline (B) & 3 Months (3m) & $\begin{array}{c}\text { B vs } \\
3 \mathrm{~m} \text { p-value }\end{array}$ & $\begin{array}{l}12 \text { Months } \\
(12 \mathrm{~m})\end{array}$ & $\begin{array}{c}\text { B vs } \\
\text { I2 m p-value }\end{array}$ \\
\hline Asthma exacerbations/year, median (IQR) & $2(0-3)$ & I & I & $0(0-1)$ & 0.0068 \\
\hline $\mathrm{ACT}$, mean (SD) & $15.7(5.1)$ & I8.8 (4.8) & 0.0230 & $22.4(1.7)$ & $<0.0001$ \\
\hline ACT MCID, n, (\%) & I & 1 & I & $12(66.7)$ & I \\
\hline ACT $\geq 20, n,(\%)$ & I & 1 & I & $16(88.9)$ & I \\
\hline $\mathrm{FEV}_{1}, \%$, mean $(\mathrm{SD})$ & $73.5(19.5)$ & $77.0(6.5)$ & 0.3733 & $87.1(19.2)$ & 0.0407 \\
\hline Patients on OCS $(n=11), n,(\%)$ & II (100) & $7(63.64)$ & 0.0902 & $0(0)$ & $<0.0001$ \\
\hline OCS, mg/die, median (IQR) & $10(5-25)$ & $0(0-5)$ & 0.0333 & $0.0(0.0-0.0)$ & $<0.0001$ \\
\hline $\begin{array}{l}\text { Eosinophil counts in peripheral blood, cells/ } \mu \mathrm{L} \\
\text { median (IQR) }\end{array}$ & $320(190-532.5)$ & $205(120-565)$ & 0.3650 & $\begin{array}{c}220 \\
(106-397.5)\end{array}$ & 0.0038 \\
\hline FeNO, ppb, median (IQR) & $25(20-80)$ & $21(10.9-55.3)$ & 0.0190 & $14(10-20)$ & 0.0066 \\
\hline
\end{tabular}

Notes: Normally distributed data are presented as mean and standard deviation (SD). Non-normally distributed variables are presented as median and interquartile range (IQR). Bold entries highlight statistically significant differences between Baseline (B) vs 3 months (3 m) and Baseline (B) vs I2 months (I2 m) of treatment.

Abbreviations: ACT, Asthma Control Test; MCID, minimal clinically important difference; FEV (prednisone); FeNO, fractional exhaled nitric oxide.

\section{Discussion}

In this multi-center, retrospective, real-world study, the dupilumab add-on treatment was able to drastically reduce the number of exacerbations and the OCSs use, improving at the same time pre-bronchodilator $\mathrm{FEV}_{1} \%$ values and asthma control.

To the best of our knowledge, this is one of the first evidences ${ }^{18,19}$ of the real-life effectiveness of dupilumab in SA patients outside clinical trials.

Patients were included in the NPP after an evaluation of their clinical characteristics and SA phenotype by physicians. Indeed, 7/18 (38.9\%) patients had a concomitant moderate-to-severe nasal polyposis, 1/18 (5.6\%) patients had an atopic dermatitis, $5 / 18$ (27.8\%) patients were previously treated with anti-IgE omalizumab and/or anti-IL-5 mepolizumab and/or were included in anti-IL-5R $\alpha$ benralizumab clinical trials, with an inadequate clinical response. Furthermore, in 8/18 (44.4\%) cases the skin prick tests for any perennial aeroallergens were negative, and the peripheral blood count was $\geq 300$ cells $/ \mu \mathrm{L}$ in $11 / 18(61.1 \%)$ cases.
A

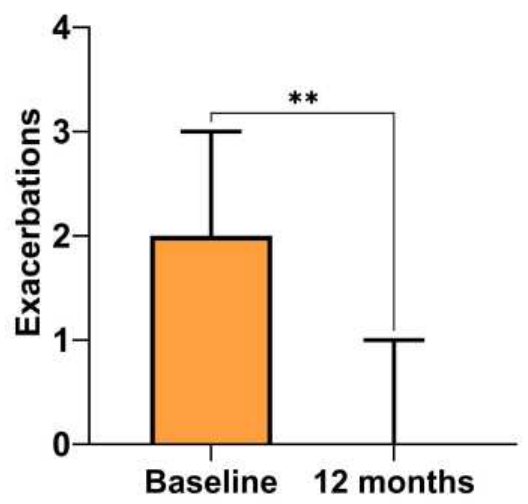

B

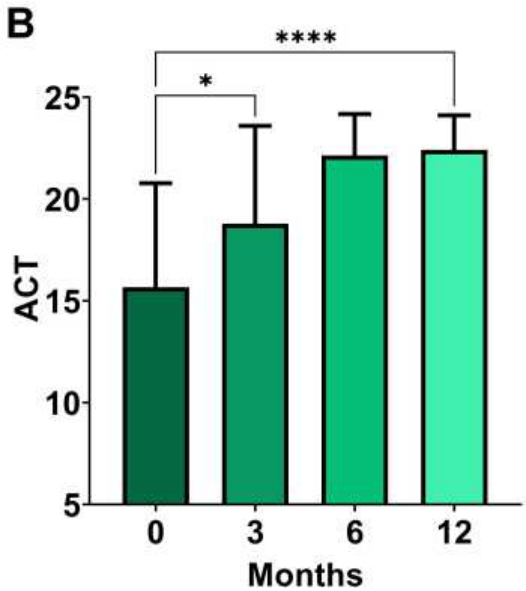

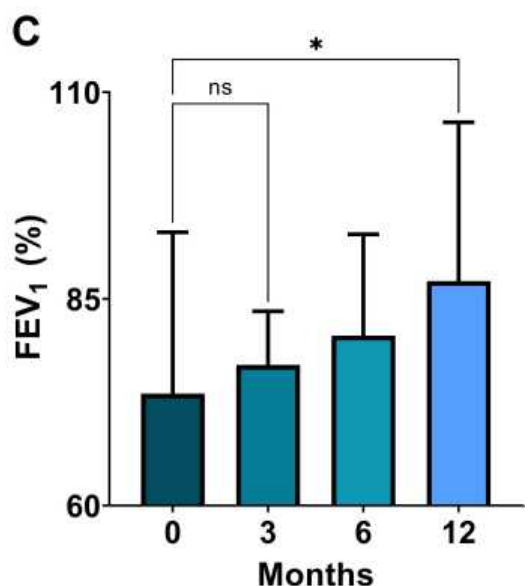

Figure I Effects of dupilumab on exacerbations (A), ACT score (B), and FEV $\%$ (C). Exacerbations are expressed as median and interquartile range (IQR). ACT and FEV values are expressed as mean and standard deviation (SD). ${ }^{*} p<0.05 ; * * p<0.01 ; * * * * p<0.0001$.

Abbreviations: ns, non-significant; ACT, Asthma Control Test; FEV , forced expiratory volume in the Ist second. 

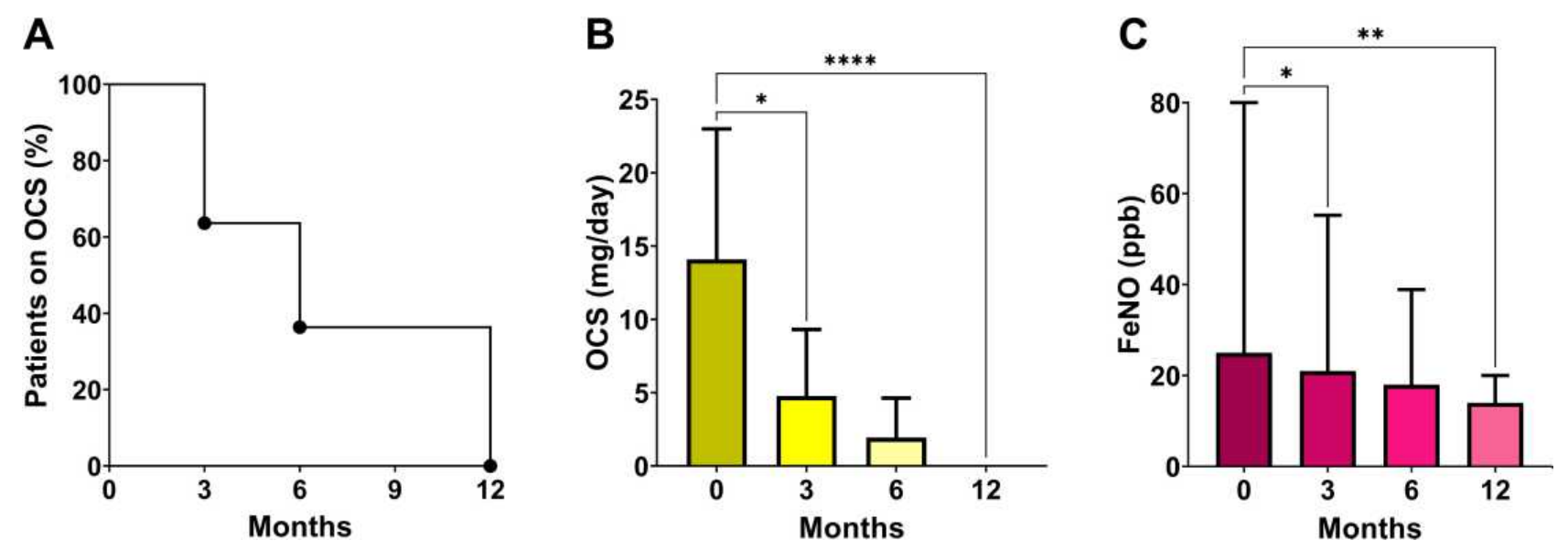

Figure 2 Effects of dupilumab on rate of patients on OCSs (A), OCSs dose (B) and FeNO values (C). The rate of patients on OCSs is expressed as a percentage (\%) from the total. OCSs dose and FeNO values are expressed as median values and interquartile range (IQR). ${ }^{*} \mathrm{p}<0.05 ;{ }^{*} *_{\mathrm{p}}<0.01 ; * * * * \mathrm{p}<0.000 \mathrm{I}$.

Abbreviations: OCSs, oral corticosteroids (prednisone); FeNO, fractional exhaled nitric oxide.

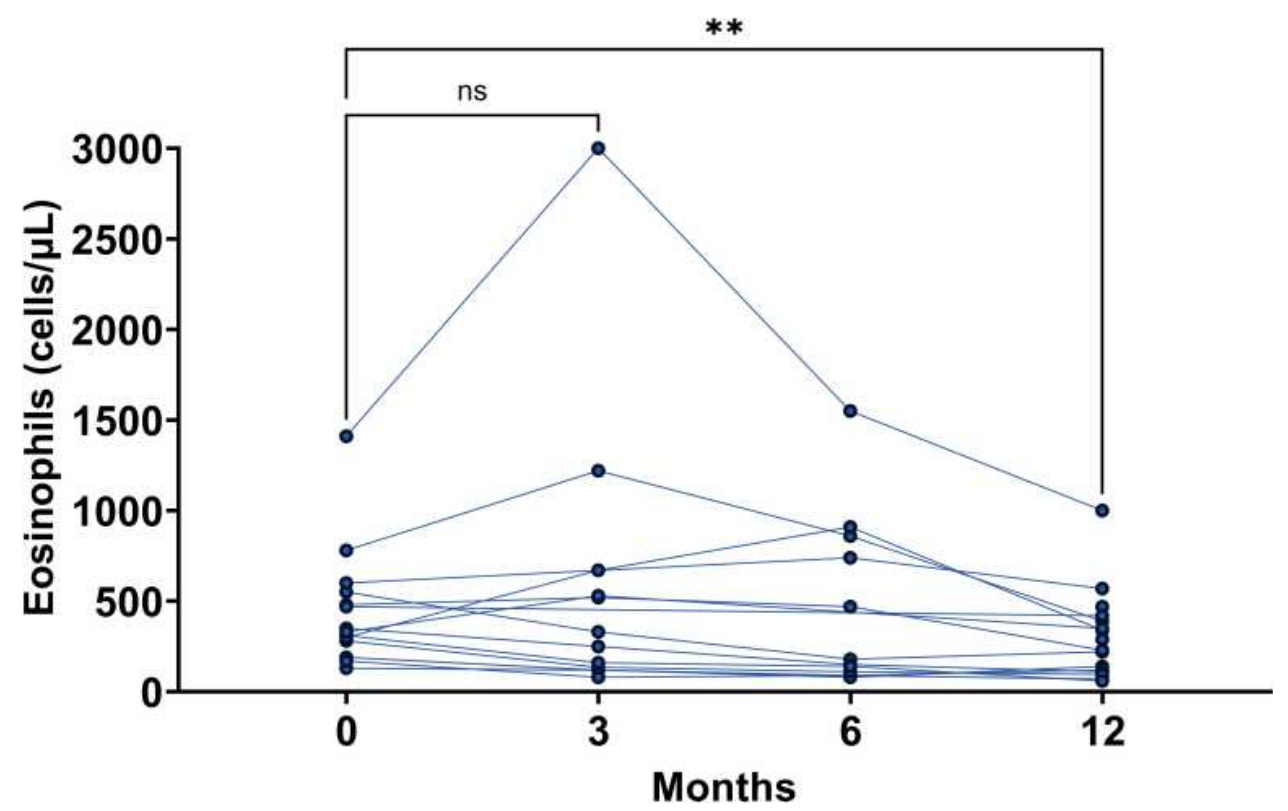

Figure 3 Peripheral blood eosinophils over the 12 months of dupilumab. Each line with dots represents a patient eosinophil count at each follow-up visit. $* *$ p $<0.01$. Abbreviation: ns, non-significant.

Due to these values, the patients could not receive omalizumab $^{20}$ or mepolizumab, ${ }^{21,22}$ the two SA monoclonal antibodies available in Italy at the time. Moreover, all these patients could not be included in dupilumab and/or benralizumab clinical trials since the enrollment was already completed or due to inclusion and exclusion criteria.

Similar to the Italian NPP, a nominative Authorization for Temporary Use (nATU) program for dupilumab early access was implemented in France in September 2017 (NCT04022447). ${ }^{18}$ Sixty-four SA patients who reached a therapeutic dead-end were enrolled in 13 French pulmonary medicine departments, regardless of their airway T2 inflammation status. Notwithstanding a high number of exacerbations (median 4 in the previous year), the OCSs consumption (mean dose $23.5 \pm 15 \mathrm{mg} /$ day) and a significantly impaired lung function (mean $\mathrm{FEV}_{1} 59 \%$ ), after one year of dupilumab add-on treatment, the number of exacerbations was reduced by $75 \%$, about $24 \%$ of patients stopped the treatment with OCSs, $78 \%$ of them were able to reduce the daily dose $\geq 50 \%$ and the $\mathrm{FEV}_{1}$ improved by $10 \%$. These results were comparable and, in some cases, superior to those obtained in clinical trials, regardless 
Table 3 Treatment Response According to Baseline Blood Eosinophil Count ( $<300$ Cells/ $\mu \mathrm{L}$ vs $\geq 300$ Cells/ $\mu \mathrm{L})$ and FeNO $(<25$ ppb vs $\geq 25 \mathrm{ppb})$

\begin{tabular}{|c|c|c|c|c|c|c|}
\hline \multirow[b]{2}{*}{$\begin{array}{l}\text { Eos }<300 \text { cells } / \mu L, n=7 \\
\text { Eos } \geq 300 \text { cells } / \mu L, n=1 \text { I }\end{array}$} & \multicolumn{2}{|c|}{ Baseline } & \multirow[b]{2}{*}{ p-value } & \multicolumn{2}{|c|}{12 Months } & \multirow[b]{2}{*}{ p-value } \\
\hline & Eos $<300$ cells $/ \mu \mathrm{L}$ & Eos $\geq 300$ cells $/ \mu \mathrm{L}$ & & Eos $<300$ cells $/ \mu \mathrm{L}$ & Eos $\geq 300$ cells $/ \mu \mathrm{L}$ & \\
\hline ACT, mean (SD) & $14.5(4.5)$ & $16.91(5.22)$ & 0.5019 & $23(0.9)$ & $21(4.42)$ & 0.4791 \\
\hline ACT MCID, n, (\%) & I & I & 1 & $7(100)$ & $10(90.9)$ & 0.9999 \\
\hline ACT $\geq 20, n,(\%)$ & I & 1 & l & $7(100)$ & $10(90.9)$ & 0.9999 \\
\hline $\mathrm{FEV}_{1}, \%$, mean $(\mathrm{SD})$ & $75.6(8.6)$ & $72.5(23.6)$ & 0.7170 & $93.2(22.7)$ & $83.8(17.5)$ & 0.4010 \\
\hline Patients on OCS $(n=\mid I), n,(\%)$ & $5(7 \mid .4)$ & $6(54.5)$ & 0.6371 & $0(0)$ & $0(0)$ & 0.9999 \\
\hline \multirow[t]{2}{*}{ OCS, mg/die, median (IQR) } & $7.5(5-20)$ & $10(5-25)$ & 0.6756 & $0(0.0-0.0)$ & $0(0.0-0.0)$ & 0.9999 \\
\hline & \multicolumn{2}{|c|}{ Baseline } & & \multicolumn{2}{|c|}{12 Months } & \\
\hline $\begin{array}{l}\text { FeNO < } 25 \text { ppb, } n=7 \\
\text { FeNO } \geq 25 \text { ppb, } n=1 \text { I }\end{array}$ & FeNO $<25$ ppb & FeNO $\geq 25$ ppb & p-value & FeNO $<25$ ppb & FeNO $\geq 25$ ppb & p-value \\
\hline$A C T$, mean $(S D)$ & I4.I (4.85) & $16.6(5.3)$ & 0.5709 & $22.4(1.6 I)$ & $21.2(4.6)$ & 0.6549 \\
\hline ACT MCID, n, (\%) & l & I & 1 & $7(100)$ & $10(90.9)$ & 0.9999 \\
\hline ACT $\geq 20, n,(\%)$ & l & l & 1 & $7(100)$ & $10(90.9)$ & 0.9999 \\
\hline $\mathrm{FEV}_{1}, \%$, mean $(\mathrm{SD})$ & $64.5(9.7)$ & $76.8(21.5)$ & 0.6852 & $76.0(2.3)$ & $83.3(34.2)$ & 0.3721 \\
\hline Patients on OCS $(n=\mid I), n,(\%)$ & $4(57.1)$ & $7(63.6)$ & 0.9999 & $0(0)$ & $0(0)$ & 0.9999 \\
\hline OCS, mg/die, median (IQR) & $10.0(5-20)$ & $12.5(5-25)$ & 0.4855 & $0(0.0-0.0)$ & $0(0.0-0.0)$ & 0.9999 \\
\hline
\end{tabular}

Notes: Normally distributed data are presented as mean and standard deviation (SD). Non-normally distributed variables are presented as median and interquartile range (IQR).

Abbreviations: Eos, eosinophils; ACT, Asthma Control Test; MCID, minimal clinically important difference; FEV ${ }_{1}$, forced expiratory volume in the Ist second; OCS, oral corticosteroids (prednisone); FeNO, fractional exhaled nitric oxide.

of the baseline value of eosinophilia $(<$ or $\geq 150$ cells/ $\mu \mathrm{L})$.

In our cohort of patients, we observed a reduction of asthma exacerbations in almost all cases in comparison to the year before, far superior to the results reported in Phase III QUEST (47.7\%) and VENTURE (59\%) trials $^{9,10}$ and in French nATU study $(75 \%){ }^{18}$ To this extent, ACT score significantly improved (approximately 3 points) after three months of treatment from baseline. Moreover, $88.9 \%$ of patients reached the critical threshold of 20 , indicative of a good overall asthma control after 12 months.

It is known that the progressive loss of lung function is a trigger of asthma exacerbations, which are responsible for airway remodeling, nurturing a loop that characterizes the physiopathology of SA..$^{23,24}$ We reported a significant statistical increase of pre-bronchodilator $\mathrm{FEV}_{1} \%$ mean value from $73.5 \%$ to $87.1 \%$ (absolute difference: $14 \%$ ) at the end of the study, which contributed to reduce the number of asthma exacerbations and to improve symptoms.

Dupilumab add-on treatment was able to reduce OCSs intake by $71.9 \%$ in glucocorticoid dependent SA in the phase III VENTURE ${ }^{10}$ trial and the French nATU study showed a $\geq$ $50 \%$ reduction of the daily dose in $78 \%$ of patients. ${ }^{18}$ In our study, $36.33 \%$ of patients progressively reduced and suspended OCSs after 3 months of treatment with dupilumab, until a complete weaning of such a noxious treatment after 12 months. Even in this case, our real-world data proved to be superior to those obtained in the clinical trial, ${ }^{10}$ despite a comparable baseline daily intake [median 10 (5-25) in our study vs mean $11.75 \pm 3.54 \mathrm{mg} /$ day after adjustment].

Taken together, all the above-mentioned findings showed that dupilumab exerted very beneficial effects already after 3 months of treatments, with a continuous trend of improvements toward the 12 months. 
Randomized controlled trials showed that baseline eosinophil counts $\geq 150$ and $\geq 300$ cells $/ \mu \mathrm{L}$ were associated with better asthma outcomes. Italian NPP, likewise French nATU, ${ }^{18}$ was designed without established inclusion criteria in terms of baseline eosinophilic counts in peripheral blood and FeNO since the results of phase III trials ${ }^{9,10}$ were not fully unveiled. For this reason, patients with a FeNO value $<25 \mathrm{ppb}$ and blood eosinophil count $<$ 150 cells $/ \mu \mathrm{L}$ were included. In our cohort, baseline blood eosinophils ( $<$ or $\geq 300$ cells $/ \mu \mathrm{L})$ or FeNO $(<$ or $\geq 25 \mathrm{ppb})$ did not affect ACT score, $\mathrm{FEV}_{1} \%$, and OCSs intake, but it is necessary to remember that the sample size of these subgroups was limited ( 7 patients for FeNO $<25$ ppb and baseline blood eosinophils $<300$ cells $/ \mu \mathrm{L}$ vs 11 patients for FeNO $\geq 25$ ppb and blood eosinophils $\geq 300$ cells $/ \mu \mathrm{L}$ ).

An asymptomatic hypereosinophilia with $\geq 1000$ cells $/ \mu \mathrm{L}$ was observed in two cases. An increase in blood eosinophil count during treatment with dupilumab could be due to the reduction of Eotaxin-3 and specific adhesion molecules, leading to an inhibition of the recruitment of the cells into the tissues, without altering their release from bone marrow, which is strongly dependent on IL-5. ${ }^{25}$ As a result, dupilumab caused transient eosinophilia in five patients without any clinical manifestations. The treatment was generally well tolerated: no patients withdrew the drugs for adverse events.

Furthermore, dupilumab represents a valid therapeutic option for non-responders to other biological therapies. In fact, in the 5 patients (27.8\%) switched from omalizumab and/or mepolizumab to dupilumab due to lack of a therapeutic response, an improvement of all clinical outcomes was observed. These data further confirm the results obtained by Mümmler et $\mathrm{al}^{19}$ : 38 SA patients switched from anti-IgE and anti-IL-5 agents to dupilumab showed greater clinical benefits in terms of exacerbation, pulmonary function, OCSs intake, and asthma symptoms.

\section{Conclusion}

In conclusion, our analysis of NPP data confirm the effectiveness of dupilumab in improving asthma outcomes in the real-life setting and transient hypereosinophilia did not modify treatment response. Although we carefully evaluated all the Italian NPP patients, this study has some limitations related to the small population involved and uncontrolled retrospective design leading to underpowered statistical analysis and reduced generalizability of the results. Indeed, larger SA cohorts treated with dupilumab in real-life settings are necessary to confirm our findings.

\section{Abbreviations}

SA, Severe Asthma; NPP, Named Patient Program; IL-4, Interleukin-4; IL-5, Interleukin-5; IL-13, Interleukin 13; CRSwNP, Chronic Rhinosinusitis with Nasal Polyps; CRSsNP, Chronic Rhinosinusitis without Nasal Polyps; AD, Atopic Dermatitis; GERD, Gastroesophageal Reflux Disease; BMI, Body Mass Index; ICS-LABA, Inhaled Corticosteroids - Long-Acting Beta-Agonist; LAMA, Long-Acting Muscarinic Antagonist; ACT, Asthma Control Test; MCID, Minimal Clinically Important Difference; $\mathrm{FEV}_{1}$, Forced expiratory volume in the 1st second; OCSs, Oral Corticosteroids (Prednisone); IgE, Immunoglobulin-E; FeNO, Fractional Exhaled Nitric Oxide.

\section{Acknowledgments}

The statistical analysis was designed and performed in collaboration with Filippo Palermo, Professor of Biostatistics at the University of Catania. Some of these data have been submitted in abstract form for a possible poster presentation at the virtual ERS International Congress 2021.

\section{Author Contributions}

All authors made substantial contributions to conception and design, acquisition of data, or analysis and interpretation of data, took part in drafting the article or revising it critically for important intellectual content, agreed to submit to the current journal, gave final approval for the version to be published, and agreed to be accountable for all aspects of the work.

\section{Funding}

This research did not receive any specific grant from funding agencies in the public, commercial, or not-forprofit sectors.

\section{Disclosure}

Prof. Dr. Alberto Papi reports grants from CHIESI, ASTRAZENECA, GSK, BI, PFIZER, TEVA, and SANOFI; personal fees from CHIESI, ASTRAZENECA, GSK, BI, MENARINI, NOVARTIS, ZAMBON, MUNDIPHARMA, TEVA, SANOFI, EDMOND PHARMA, IQVIA, MSD, AVILLION, and ELPEN PHARMACEUTICALS, outside 
the submitted work. The authors report no other conflicts of interest in this work.

\section{References}

1. Holguin F, Cardet JC, Chung KF, et al. Management of Severe Asthma: a European Respiratory Society/American Thoracic Society Guideline. Eur Respir J. 2019. doi:10.1183/ 13993003.00588-2019).

2. Hekking PP, Wener RR, Amelink M, Zwinderman AH, Bouvy ML, Bel EH. The prevalence of severe refractory asthma. J Allergy Clin Immunol. 2015;135(4):896-902. doi:10.1016/j.jaci.2014.08.042

3. Global Initiative for Asthma (GINA). GINA Report, global strategy for asthma management and prevention; 2019. Available from: http// ginasthma.org. Accessed February 05, 2021.

4. Lefebvre P, Duh MS, Lafeuille MH, et al. Acute and chronic systemic corticosteroid-related complications in patients with severe asthma J Allergy Clin Immunol. 2015;136(6):1488-1495. doi:10.1016/j. jaci.2015.07.046

5. Israel E, Reddel HK. Severe and difficult-to-treat asthma in adults. N Engl J Med. 2017;377(10):965-976. doi:10.1056/NEJMra1608969

6. Pelaia C, Vatrella A, Gallelli L, et al. Dupilumab for the treatment of asthma. Expert Opin Biol Ther. 2017;17(12):1565-1572. doi:10.1080/14712598.2017.1387245

7. Beck LA, Thaçi D, Hamilton JD, et al. Dupilumab treatment in adults with moderate-to-severe atopic dermatitis. $N$ Engl J Med. 2014;371 (2):130-139. doi:10.1056/NEJMoa1314768

8. Bachert C, Han JK, Desrosiers M, et al. Efficacy and safety of dupilumab in patients with severe chronic rhinosinusitis with nasal polyps (LIBERTY NP SINUS-24 and LIBERTY NP SINUS-52): results from two multicentre, randomized, double-blind, placebo-controlled, parallel-group Phase 3 trials. Lancet. 2019;394 (10209):1638-1650. doi:10.1016/S0140-6736(19)31881-1

9. Castro M, Corren J, Pavord ID, et al. Dupilumab efficacy and safety in moderate-to-severe uncontrolled asthma. $N$ Engl J Med. 2018;378 (26):2486-2496. doi:10.1056/NEJMoa1804092

10. Rabe KF, Nair P, Brusselle G, et al. Efficacy and safety of dupilumab in glucocorticoid-dependent severe asthma. $N$ Engl J Med. 2018;378 (26):2475-2485. doi:10.1056/NEJMoa1804093

11. Wenzel S, Castro M, Corren J, et al. Dupilumab efficacy and safety in adults with uncontrolled persistent asthma despite medium-to-highdose inhaled corticosteroids plus a long-acting $\beta 2$ agonist: a randomized, double-blind placebo-controlled pivotal phase $2 \mathrm{~b}$ doseranging trials. Lancet. 2016;388(10039):31-44. doi:10.1016/S01406736(16)30307-5

12. Nathan RA, Sorkness CA, Kosinski M, et al. Development of the asthma control test: a survey for assessing asthma control. $J$ Allergy Clin Immunol. 2004;113(1):59-65. doi:10.1016/j.jaci.2003.09.008
13. Crimi C, Campisi R, Noto A, et al. Comparability of asthma control test scores between self and physician-administered test. Respir Med. 2020;170:106015. doi:10.1016/j.rmed.2020.106015

14. Reddel HK, Taylor DR, Bateman ED, et al. An official American Thoracic Society/European Respiratory Society statement: asthma control and exacerbations: standardizing endpoints for clinical asthma trials and clinical practice. Am J Respir Crit Care Med. 2009;180(1):59-99. doi:10.1164/rccm.200801-060ST

15. Miller MR, Hankinson J, Brusasco V, et al. Standardisation of spirometry. Eur Respir J. 2005;26(2):319-338. doi:10.1183/ 09031936.05.00034805

16. Schatz M, Kosinski M, Yarlas AS, Hanlon J, Watson ME, Jhingran P. The minimally important difference of the Asthma Control Test. $J$ Allergy Clin Immunol. 2009;124(4):719-23.e1. doi:10.1016/j. jaci.2009.06.053

17. Agarwal R, Chakrabarti A, Shah A, et al. Allergic bronchopulmonary aspergillosis: review of literature and proposal of new diagnostic and classification criteria. Clin Exp Allergy. 2013;43(8):850-873. doi:10.1111/cea.12141

18. Dupin C, Belhadi D, Guilleminault L, et al. Effectiveness and safety of dupilumab for the treatment of severe asthma in real-life French multicentre adult cohort. Clin Exp Allergy. 2020;50:789-798. doi:10.1111/cea.13614

19. Mümmler C, Munker D, Barnike M, et al. Dupilumab improves asthma control and lung function in patients with insufficient outcome during previous antibody therapy. $J$ Allergy Clin Immunol Pract. 2020;9:1177-1185.e4. doi:10.1016/j.jaip.2020.09.014

20. Campisi R, Crimi $C$, Intravaia R, et al. Adherence to omalizumab: a multicenter "real-world" study. World Allergy Organ J. 2020;13 (2):100103. doi:10.1016/j.waojou.2020.100103

21. Crimi C, Campisi R, Cacopardo G, et al. Real-life effectiveness of mepolizumab in patients with severe refractory eosinophilic asthma and multiple comorbidities. World Allergy Organ J. 2020;13 (9):100462. doi:10.1016/j.waojou.2020.100462

22. Pelaia C, Crimi C, Pelaia G, et al. Real-life evaluation of mepolizumab efficacy in patients with severe eosinophilic asthma, according to atopic trait and allergic phenotype. Clin Exp Allergy. 2020;50 (7):780-788. doi:10.1111/cea.13613

23. Dougherty RH, Fahy JV. Acute exacerbations of asthma: epidemiology, biology, and the exacerbation-prone phenotype. Clin Exp Allergy. 2009;39(2):193-202. doi:10.1111/j.1365-2222.2008.03157.x

24. Bai TR, Vonk JM, Postma DS, Boezen HM. Severe exacerbations predict excess lung function decline in asthma. Eur Respir J. 2007;30 (3):452-456. doi:10.1183/09031936.00165106

25. Fulkerson PC, Rothenberg ME. Targeting eosinophils in allergy, inflammation and beyond. Nat Rev Drug Discov. 2013;12 (2):117-129. doi:10.1038/nrd3838

Journal of Asthma and Allergy

Dovepress

\section{Publish your work in this journal}

The Journal of Asthma and Allergy is an international, peer-reviewed open-access journal publishing original research, reports, editorials and commentaries on the following topics: Asthma; Pulmonary physiology; Asthma related clinical health; Clinical immunology and the immunological basis of disease; Pharmacological interventions and

new therapies. The manuscript management system is completely online and includes a very quick and fair peer-review system, which is all easy to use. Visit http://www.dovepress.com/testimonials.php to read real quotes from published authors. 